\title{
Is there a benefit of first- or second-line crizotinib in locally advanced or metastatic anaplastic lymphoma kinase-positive non-small cell lung cancer? a meta-analysis
}

\author{
Hao Hu${ }^{1, *}$, Wei Qing Lin ${ }^{2,6, *}$, Qian Zhu ${ }^{3, *}$, Xiong Wen Yang ${ }^{1}$, Hai Dong Wang ${ }^{4}$, \\ Yu Kang Kuang ${ }^{5}$ \\ ${ }^{1}$ Department of Thoracic Surgery, Medical College of Nanchang University, Nanchang, 330006, China \\ ${ }^{2}$ Department of Integrated Chinese and Western Medicine, Medical College of Nanchang University, Nanchang, 330006, China \\ ${ }^{3}$ Department of Biotherapy, Sun Yat-sen University Cancer Center, Guangdong, 510060, China \\ ${ }^{4}$ Department of General Surgery, Medical College of Nanchang University, Nanchang, 330006, China \\ ${ }^{5}$ Department of Thoracic Surgery, Medical College of Nanchang University, Jiangxi Province Tumor Hospital, Nanchang, \\ 330006, China \\ ${ }^{6}$ Department of Integrated Chinese and Western Medicine, Jiangxi Province People's Hospital, Nanchang, 330006, China \\ *These authors contributed equally to this work
}

Correspondence to: Yu Kang Kuang, email: kuangyukang@aim.com

Keywords: meta-analysis, crizotinib, anaplastic lymphoma kinase, non-small cell lung cancer

Received: April 23, $2016 \quad$ Accepted: October 31, $2016 \quad$ Published: November 07, 2016

\section{ABSTRACT}

Background: Crizotinib show a promising efficacy in patients with anaplastic lymphoma kinase (ALK)-positive non-small cell lung cancer (NSCLC). However, differences in efficacy for first- and second-line crizotinib are unclear.

Results: The pooled overall response rate and progression-free survival were $65 \%$ and 9.38 months, respectively. In the subgroup analysis, first-line crizotinib showed a higher trend of overall response rate and longer trend of progression-free survival although there was no statistical difference between first-line and secondline crizotinib (74\%, 11.28 months vs. $65 \%$, 8.12 months, respectively; fixed effects model). Moreover, overall response rate between Asians and Caucasians were similar (67\% and $66 \%$, respectively; fixed effects model).

Materials and Methods: A comprehensive search of MEDLINE, EMBASE, WEB OF SCIENCE and the COCHRANE databases from their inception to February 2016 was performed to identify clinical trials in English-language journals. Pooled overall response rate, progressionfree survival and differences between first- and second-line crizotinib were estimated. Moreover, overall response rate between Asians and Caucasians were also estimated.

Conclusions: First-line crizotinib may more effective than second-line crizotinib for patients with locally advanced or metastatic ALK-positive NSCLC.

\section{INTRODUCTION}

According to the report of the World Health Organization, lung cancer is the leading incidence and the 5 -year prevalence is about $36.5 \%$ in the world [1]. Nonsmall cell lung cancer (NSCLC) is the most common type of lung cancer and anaplastic lymphoma kinase (ALK) gene rearrangement has been demonstrated to be associated with approximately $2-7 \%$ of NSCLCs. ALK gene rearrangement is uncommon, however, it is more prevalent in younger patients who tend to be non-smokers or light smokers and who have adenocarcinomas [2, 3]. Crizotinib was approved by the United States Food and Drug Administration (FDA) in
2013 to treat patients with metastatic ALK-positive NSCLC and it is now approved in more than 85 countries [4]. The PROFILE 1001 study revealed that crizotinib achieved good efficacy and well tolerance in the treatment of ALK-positive NSCLC [5]. The PROFILE 1014 and PROFILE 1007 studies demonstrated that crizotinib was superior to chemotherapy in the first-line and the second-line settings, respectively $[6,7]$; the efficacy and safety data from PROFILE 1029 study will be submitted for presentation at a future medical meeting [8]. Now new clinical trials, comparing next generation of ALK inhibitors with crizotinib, are ongoing (e.g. alectinib in the ALEX trial, ceritinib in the ASCEND-4 trial, brigatinib in the ALTA-1L trial). 
A meta-analysis of clinical trials revealed that crizotinib was associated with a promising overall response rate (ORR: 61.2\%, 95\% confidence interval [CI]: 57.4-64.8\%) and progression-free survival (PFS: 8.6 months [95\% CI, 7.3-9.9 months]) in patients with locally advanced or metastatic ALK-positive NSCLC [9]. With the rapid development in oncology research and the increased number of clinical trials in recent years, updated data for crizotinib are available. However, the discrepancies in efficacy between first-line and second-line crizotinib are unclear. The objectives of this meta-analysis were evaluating the efficacy of crizotinib, assessing ORR between Asians and Caucasians, comparing the efficacy according to line of treatment in patients with locally advanced or metastatic ALK-positive NSCLC.

\section{RESULTS}

\section{Primary characteristics of all studies}

Our search yielded a total of 6086 articles. After evaluating each publication, we identified 13 original studies (representing 14 clinical trials; 1 study included 2 trials) [5-7, 10-19] that met our inclusion criteria. The details of our search results could be seen in the flow diagram (Figure 1). Among these 13 studies (including 11 non randomized control trials [NRCTs] and 2 randomized control trials [RCTs]), 3 studies described first-line therapies [7, 16, 17], 3 studies described second-line therapies $[6,11,16]$ and 7 studies described mixed therapies $[5,10,12-15,19]$. Moreover, 8 studies reported median PFS and 95\% CI [5-7, 10, 13, 15, 16, 19]. The primary characteristics of the selected studies were listed in Table 1.

\section{Study quality assessment and risk of bias}

We summarized the methodological quality of all the NRCTs (excluding the abstracts only and conferences) in the Supplementary Table S1. The NOS results showed that the average overall score was 5.6 (range 5-7). None of the included studies had major flaws in assessment of their risk of bias. A common caveat, however, was the expected absence of blinded intervention. A detailed assessment of risk of bias was summarized in Supplementary Table S2.

\section{Pooled ORR of all studies}

Among the 13 studies [5-7, 10-19], the pooled ORR for crizotinib was investigated for treating ALKpositive NSCLC. An analysis of the pooled data revealed a pooled ORR (Figure 2) of 64\% (95\% CI, 59-69\%, df $=12$, $\left.I^{2}=58.7 \%, P<0.01\right)$

For subgroups, a higher trend of first-line crizotinib for ORR could be seen although there was no statistical difference between first-line and second-line crizotinib. The ORR for first-line and second-line crizotinib were
74\% (95\% CI: 68-81\%) and 65\% (95\% CI: 59-72\%), respectively (Figure 3A). The pooled ORR of all patients who received crizotinib as either first- or secondline treatment was 70\% (95\% CI: $66-75 \%, I^{2}=0.0 \%$, $P=0.495$ ) (Figure 3A). In the subgroup analysis of race, there were 8 studies that could be assessed $[11-17,19]$. However, none statistically significant difference of ORR between Asians and Caucasians was detected (ORR, $67 \%$ [95\% CI, 62-73\%] and 66\% [95\% CI, 58-76\%], respectively) (Figure 3B).

There was significant heterogeneity between studies in the pooled ORR analysis $\left(I^{2}=58.7 \%, P<0.01\right)$. When stratified by study design, the heterogeneity was still significant for NRCTs and RCTs (Figure 2). From the results of the leave-one-out sensitivity analysis, all of the above results were not materially altered (data not shown). We found no evidence of publication bias in any analyses using Begg's $(P=0.669)$ and Egger's tests $(P=0.481)$.

\section{Pooled PFS of all studies}

There were 8 studies on the relationship of crizotinib use and PFS in ALK-positive NSCLC [5-7, 10, 13, $15,16,19]$. An analysis of the pooled data revealed a pooled PFS (Figure 4A) of 9.38 months (95\% CI, 8.6710.14 months, $\left.\mathrm{df}=7, I^{2}=49.8 \%, P>0.05\right)$.

In the subgroup analysis between first-line and second-line crizotinib $[6,7,16]$ (the study of Cui et al. [16] described 2 trials), the differences in PFS between first-line and second-line crizotinib treatment were not statistically significant (PFS, 11.28 months [95\% CI, 8.93-14.26 months] and 8.29 months [95\% CI, 6.62-10.38 months], respectively) (Figure 4B).

There was no significant heterogeneity between studies in the pooled PFS analysis $\left(I^{2}=49.8 \%, P>0.05\right)$. From the results of the leave-one-out sensitivity analysis, all of the above results were not materially altered (data not shown). We also found no evidence of publication bias in any analyses using Begg's $(P=1)$ and Egger's tests $(P=0.678)$.

\section{DISCUSSION}

We identified 6086 articles for review of title and abstract (Figure 1). After initial screening, we retrieved 20 potentially eligible articles for detailed data assessment. Four studies [20-23] were excluded with insufficient data: undescribed ORR and PFS. Three studies [3, 24, 25] from same trials were not the latest article with the most complete data and thus were excluded: one study [3] from PROFILE 1001 (ORR, 57\%, 95\% CI, 46-68\%; median PFS was not reached) and two studies [24, 25] from PROFILE 1005 (one study didn't reported ORR and median PFS, another study reported ORR, $46 \%$, 95\% CI, 42-50\%; median PFS 8.1 months, 95\% CI, 6.8-9.7 months). Therefore, the rest 13 articles were included in this meta-analysis. 
In the present research, the ORR and PFS for crizotinib in the treatment of locally advanced or metastatic ALK-positive NSCLC were about $65 \%$ and 9.38 months, regardless of when crizotinib was used. Subgroup analysis between Asians and Caucasians showed the ORR of crizotinib was similar $(67 \%$ vs. $66 \%$, respectively). Therefore, crizotinib showed promising responses in both Asians and Caucasians with locally advanced or metastatic ALK-positive NSCLC. Moreover, the cumulative ORR and PFS for patients treated with first-line crizotinib were $74 \%$ and 11.28 months, respectively, in comparison to $65 \%$ and 8.12 months, respectively, for patients applied with second-line crizotinib. However, statistical significant difference was not detected between first-line and secondline crizotinib. Cui S et al. showed that the ORR was lower among those who received multiple-line (third-line or later) treatment prior to crizotinib therapy $(P=0.702)$ [15]. Thus, first-line crizotinib should be recommended as first-line treatment to patients with locally advanced or metastatic ALK-positive NSCLC [26]. Additionally, the National Comprehensive Cancer Network (NCCN) guideline (Version 1.2015) suggested crizotinib should be chose as first-line treatment for any performance status of ALK positive lung cancer [26]. Previous study indicated that crizotinib may enhance the efficacy of chemotherapeutic drugs especially for the patients with multidrug resistance in cancer chemotherapy [27]. However, for the patients with ALK mutation detected during first-line chemotherapy, crizotinib should be utilized immediately or started after completing chemotherapy. For the patients with cancer progression after taking crizotinib, ceritinib should be started or keep taking crizotinib basing on whether the cancer causing symptoms or not [26].
Numerous clinical trials showed crizotinib treatment could prolong PFS and improve ORR [5-7]. Some novel findings have been found to be correlated with the response and PFS to crizotinib. Fluorescence in situ hybridization analysis demonstrated the percentage of ALK-positive cells was weakly correlated with the response to crizotinib [28]. Lei et al. showed that the ORR of crizotinib was similar between patients with and without brain metastases at baseline in Chinese patients with ALK-positive NSCLC (68.4\% vs. $69.5 \%, P=0.904)$ [19]. For patients with coalterations of epidermal growth factor receptor (EGFR) mutations and ALK translocation, crizotinib also appeared to be effective $[15,29]$. Many researches indicated the response rate seemed to be largely independent of age, sex, performance status, line of treatment, radical surgery history, histologic type and previous treatment received [5, $13,15]$. However, the patients with baseline good $(0-2)$ performance status (PS) had a better PFS than those with poor ( $>3$ ) PS ( 50 weeks vs. 24 weeks, $P=0.015$ ) [13]. Moreover, the patients without brain metastases at baseline have an extended median PFS (10.0 months, 95\% CI, 7.6-12.5 vs. 7.0 months, $95 \%$ CI, 6.4-7.6; $P=0.021$ ) [19]. Additionally, ALK-positive NSCLC patients with emergent central nervous system disease were more likely to benefit from treatment [30]. Although crizotinib showed good efficacy in most patients with ALK-positive NSCLC, patients invariably relapse typically within 1 year because of the intrinsic or acquired drug resistance [31]. Inhibitors of heat shock protein and second-generation ALK-inhibitor (ceritinib, alectinib, et al.) may have the potential to overcome the resistance to crizotinib [31-34].

Prospectively randomized clinical trials compared second-generation ALK inhibitors with crizotinib in the
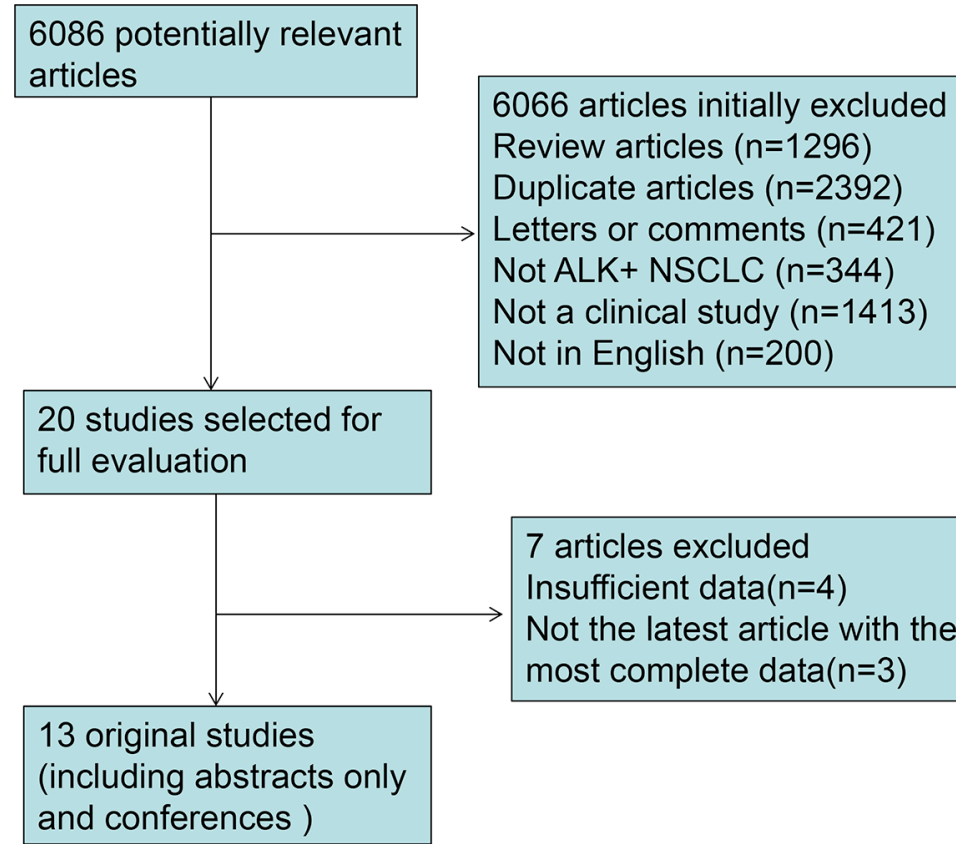

Figure 1: Flow diagram of the review. ALK + NSCLC, anaplastic lymphoma kinase-positive non-small cell lung cancer. 
Table 1: Primary characteristics of the selected studies

\begin{tabular}{|c|c|c|c|c|c|c|c|c|c|c|}
\hline Study & $\begin{array}{l}\text { Study } \\
\text { design }\end{array}$ & $N$ & $\begin{array}{c}\text { Median } \\
\text { age }\end{array}$ & $\begin{array}{c}\text { Female } \\
(\%)\end{array}$ & $\begin{array}{c}\text { Never } \\
\text { smoking } \\
(\%)\end{array}$ & $\begin{array}{c}\text { Adeno- } \\
\text { carcinoma } \\
(\%)\end{array}$ & Race $(\%)$ & $\begin{array}{c}\text { Brain } \\
\text { metastases } \\
(\%)\end{array}$ & $\begin{array}{c}\begin{array}{c}\text { Line of } \\
\text { therapy } \\
(\geq \text { Third, }[\%])\end{array}\end{array}$ & $\begin{array}{c}\text { ECOG PS } \\
\text { score } \leq 1 \\
(\%)\end{array}$ \\
\hline $\begin{array}{l}\text { Camidge } \\
\text { D Ross [5] }\end{array}$ & NRCTS & 149 & 52 & 51 & 71 & 97 & $\begin{array}{c}\text { Caucasian } 64 \\
\text { Asian } 28 \\
\text { Other } 9\end{array}$ & 0 & $\begin{array}{c}\text { Mixed-line } \\
(53 \%)\end{array}$ & 48 \\
\hline Kim, D. W [10] & NRCTS & 255 & 53 & 53 & 65 & 92 & NA & NA & $\begin{array}{c}\text { Mixed-line } \\
(85 \%)\end{array}$ & 83 \\
\hline T. Asao [11] & NRCTS & 6 & 54 & 50 & NA & NA & Asian 100 & NA & Second-line & 67 \\
\hline M. Perol [12] & NRCTS & 254 & 57 & 50 & NA & NA & Caucasian 100 & 31 & $\begin{array}{c}\text { Mixed-line } \\
(53 \%)\end{array}$ & 76 \\
\hline Berta [14] & NRCTS & 10 & 56 & 70 & 40 & 90 & Caucasian 100 & NA & $\begin{array}{l}\text { Mixed-line } \\
(60 \%)\end{array}$ & NA \\
\hline Evelyn M. Brosnan [18] & NRCTS & 38 & 54.7 & 47.4 & NA & NA & $\begin{array}{c}\text { Caucasian } 94.7 \\
\text { Asian } 0.02 \\
\text { Other } 0.02\end{array}$ & NA & NA & NA \\
\hline CaoYabing [13] & NRCTS & 40 & 42 & 42.5 & NA & 100 & Asian 100 & NA & $\begin{array}{c}\text { Mixed-line } \\
(42.5 \%)\end{array}$ & NA \\
\hline Cui, Shaohua [15] & NRCTS & 72 & 55 & 52.8 & 72.2 & 94.40 & Asian 100 & 0 & $\begin{array}{l}\text { Mixed-line } \\
(25 \%)\end{array}$ & 97 \\
\hline Lei, Y. Y [19] & NRCTS & 120 & 48 & 49.2 & 78.3 & 96.7 & Asian 100 & 31.6 & $\begin{array}{l}\text { Mixed-line } \\
\text { (NA) }\end{array}$ & 93.7 \\
\hline Cui, S. a [16] & NRCTS & 80 & 54 & 52 & 74 & NA & Asian 100 & 0 & $\begin{array}{l}\text { First-line/ } \\
\text { second-line }\end{array}$ & 97 \\
\hline Zhang, Q [17] & NRCTS & 19 & 53 & 42.9 & 85.7 & NA & Asian 100 & NA & First-line & 100 \\
\hline Alice T. Shaw [6] & RCTS & 173 & 51 & 57 & 62 & 95 & $\begin{array}{c}\text { Caucasian } 52 \\
\text { Asian } 46 \\
\text { Other } 2\end{array}$ & 35 & Second-line & 91 \\
\hline Benjamin J. Solomon [7] & RCTS & 172 & 52 & 60 & 62 & 84 & $\begin{array}{c}\text { Caucasian } 53 \\
\text { Asian } 45 \\
\text { Other } 2\end{array}$ & 26 & First-line & 94 \\
\hline
\end{tabular}

a This study included two subgroups of trials: one underwent first-line treatment and the other underwent second-line treatment.

Abbreviations: NA, Not available; NRCTS, Non-randomized controlled trials; RCTS, Randomized controlled trials.

ECOG PS, Eastern Cooperative Oncology Group performance status.

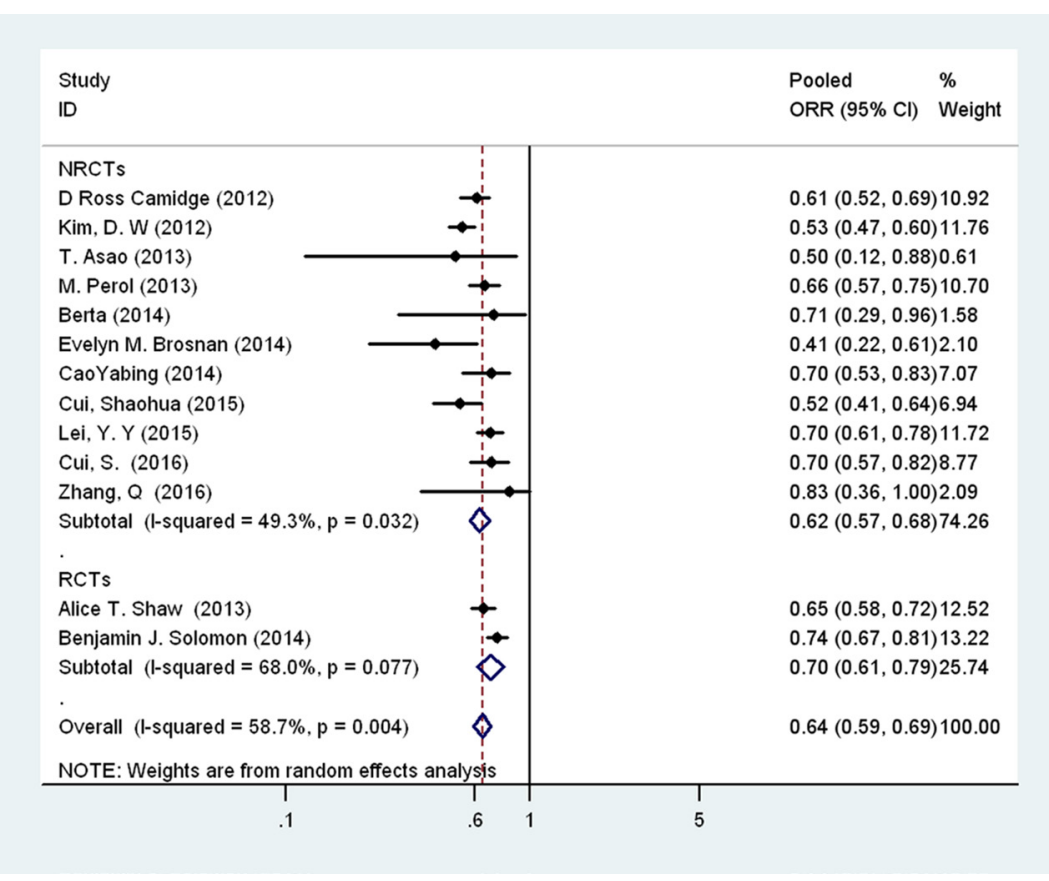

Figure 2: Forest plot showing the pooled overall response rate of patients with anaplastic lymphoma kinase (ALK)positive non-small cell lung cancer (NSCLC) to crizotinib. 
first-line setting are ongoing $[35,36]$. However, singlearm trials showed that second-generation ALK inhibitor had clinical activity in patients with crizotinib-refractory or crizotinib-resistant ALK-positive NSCLC [37-39]. Moreover, J-ALEX study indicated that alectinib (secondgeneration ALK inhibitors) reduced the risk of disease worsening or death by 66 percent compared to crizotinib $((\mathrm{HR}=0.34,99$ percent $\mathrm{CI}: 0.17-0.70, p<0.0001)$ and had the potential to become first-line therapy in patients with ALK-positive NSCLC [40]. Ceritinib (secondgeneration ALK inhibitors) showed better efficacy in ALK inhibitor-naive patients than ALK inhibitor-pretreated (all had received crizotinib, and five patients had also received alectinib) patients (ORR, 72\% vs 56\%; median PFS, 18.4 months vs 6.9 months) [37]. Similarly, alectinib (secondgeneration ALK inhibitors) showed longer PFS (the lowest PFS was 20.3 months) in the first-line treatment than

A

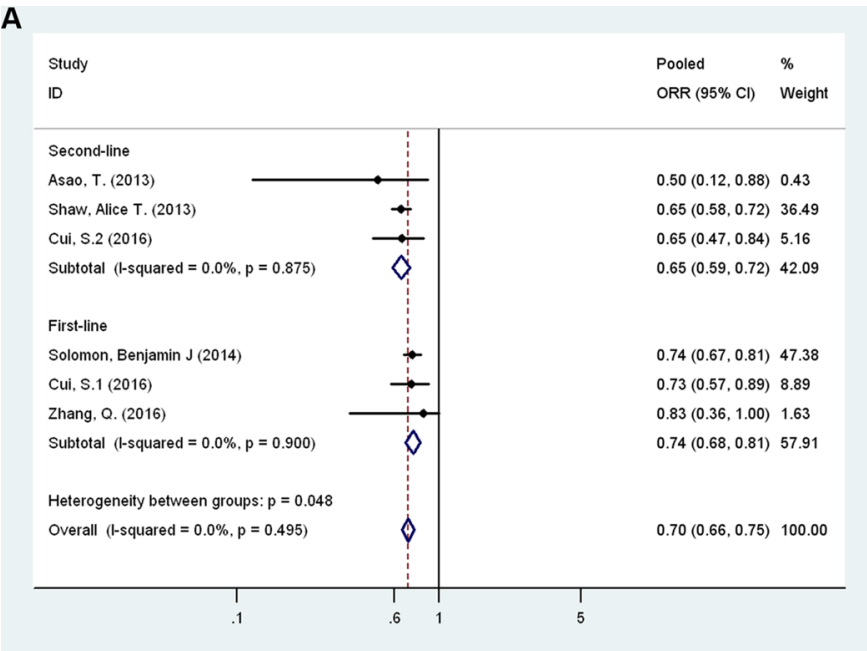

second- and later-line treatment (the highest PFS was 11.3 months) $[38,40]$. Consistent with the above results, present study indicated that crizotinib showed a trend of better efficacy in the first-line treatment than the secondand later-line treatment for patients with locally advanced or metastatic ALK-positive NSCLC; however, statistical significant difference was undetected.

Our meta-analysis has some important limitations. Although a sensitivity analysis was performed, a major limitation is the heterogeneity that existed among the results of all included studies. Moreover, this was a metaanalysis of summary estimates rather than an analysis of individual patient data, which could have provided further insight into the efficacy of the crizotinib treatment. Therefore, the results should be interpreted prudently; compared to an individual patient database systematic review based on abstracted data or published data that

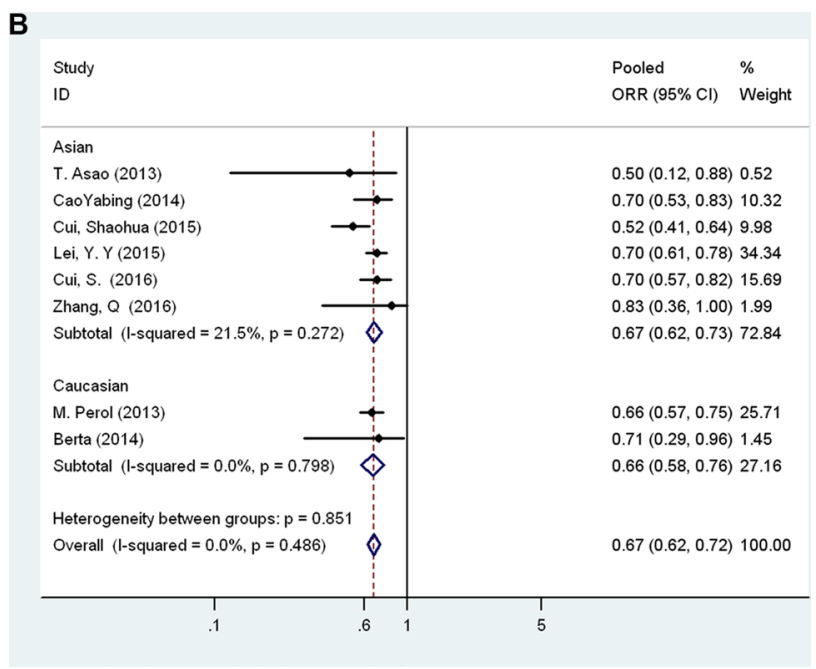

Figure 3: (A) Forest plot comparing the overall response rate to first-line and second-line therapy by patient subgroup. (B) Forest plot comparing the overall response rate for Asians and Caucasians by patient subgroup.

A

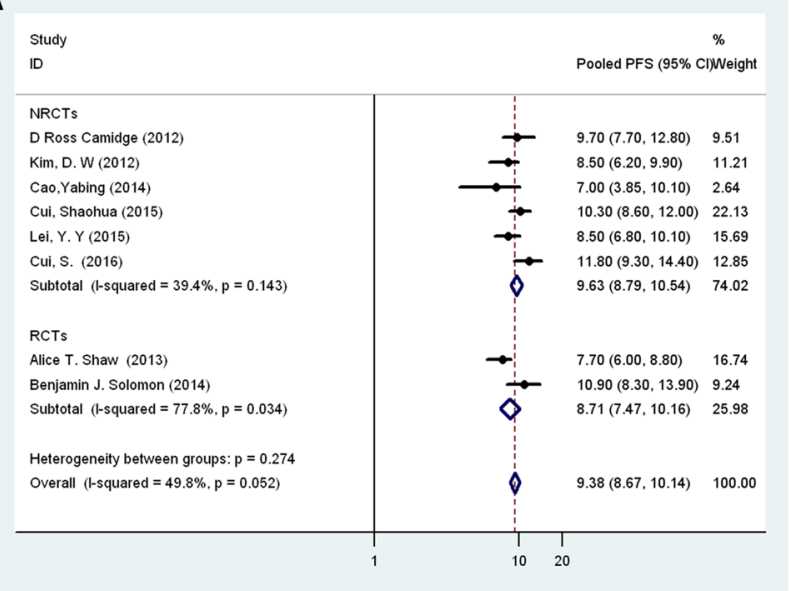

B

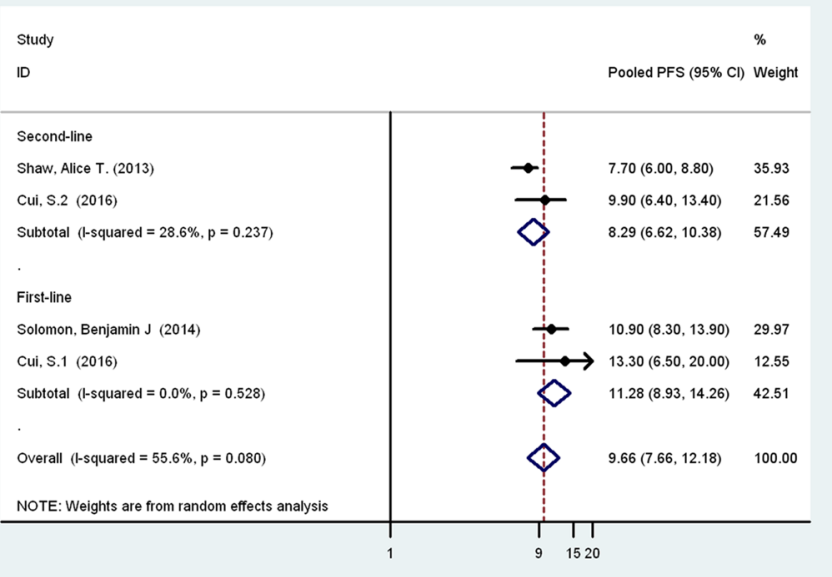

Figure 4: (A) Forest plot comparing progression-free survival to first-line and second-line therapy by patient subgroup. (B) Forest plot comparing progression-free survival by Asians and Caucasians by patient subgroup. 
would lack reliable evaluation. Additionally, publication bias might have occurred because we did not include unpublished data, although evidence of publication bias was not found based on results of the Begg's test and Egger's test. Finally, the number of studies included that used first-line and second-line therapy was small, so statistical power was limited.

In conclusion, the meta-analysis estimated the pooled ORR and PFS of crizotinib in patients with locally advanced or metastatic ALK-positive NSCLC and compared the efficacy of first-line and second-line treatment. Our analysis demonstrated that among patients with locally advanced or metastatic ALK-positive NSCLC, crizotinib showed effective response rate and appears to be a favourable treatment option. Moreover, first-line crizotinib may more effective in comparison with second-line crizotinib for patients with locally advanced or metastatic ALK-positive NSCLC. However, further multicentre, RCTs with larger sample sizes are needed to compare the efficacy of first-line and secondline therapy.

\section{MATERIALS AND METHODS}

\section{Search strategy for identifying studies}

A comprehensive search of the MEDLINE, EMBASE, WEB OF SCIENCE, and COCHRANE databases from their inception to February 2016 was performed to identify clinical trials in English-language journals. The following medical subject heading (MeSH) terms and text words were used in combination: "pulmonary" or "lung", "cancer" or "tumour" or "carcinoma", "ALK" or "anaplastic lymphoma kinase", "crizotinib".

According to the PICO checklist, eligibility criteria were as follows: (1) population: patients with locally advanced or metastatic anaplastic lymphoma kinase-positive non-small cell lung cancer; (2) intervention: crizotinib; (3) control: none; (4) outcome: ORR (defined as the observed survival rate of patients since the date of crizotinib treatment) and PFS (time from beginning of treatment to non-small cell lung cancer recurrence or death).

We also manually searched the reference lists of all pertinent studies. Meeting abstracts from the American Society of Clinical Oncology, the European Society for Medical Oncology and ClinicalTrials.gov were also handsearched to identify eligible trials. Finally, reference lists of original articles and review articles were also searched. The corresponding authors of some studies were contacted for further information if necessary. Our analyses were conducted in accordance with the Preferred Reporting Items for Systematic Reviews and Meta-analyses (PRISMA) guidelines (when appropriate) for a systematic review of prevalence [41].

\section{Study selection}

All clinical trials that explored the efficacy of crizotinib for the treatment of locally advanced or metastatic ALK-positive NSCLC were considered eligible for analysis. The inclusion criteria were as follows: (1) articles were clinical trials investigating the efficacy of crizotinib for the treatment of patients with locally advanced or metastatic ALK-positive NSCLC; (2) a standardized effect size could be calculated on the evaluations of ORR and PFS; (3) articles were in English and the dose and frequency of crizotinib administration was $250 \mathrm{mg}$ twice daily, which was approved by the FDA; (4) the included study must have sufficient data available for extraction; (5) when multiple articles were based on the same trial, only the latest article with the most complete data was included for this meta-analysis. Two investigators (X. Yang and H. Wang) independently assessed the articles for relevance to our study.

\section{Study quality assessment}

The full texts of non-randomized clinical trials were assessed using the 9-point Newcastle Ottawa scale (NOS) by two investigators (H.D. Wang and Q. Zhu). Two investigators independently evaluated each study based on eight items, categorized into three broad perspectives including selection, comparability and outcome for cohort studies or exposure for case-control studies [42]. We considered studies with a score of 7 or greater as high quality. Risk of bias in the included studies was independently assessed by two investigators using the Cochrane collaboration's tool for assessing risk of bias in randomized control trials (RCTs) [43]. Each study was independently assessed by two authors (H.D. Wang and Q. Zhu) under five main headings for risk of bias. Disagreements were resolved by discussion or through consultation with the senior reviewer.

\section{Data extraction}

According to the inclusion and exclusion criteria, two of our investigators independently completed the retrieval process. For each article, we collected the first author, year of publication, number of patients enrolled, number of patients analysed, therapeutic regimen, demographic factors (such as age and histologic type), ORR and PFS for patients. We collected the data of each line of clinical trials through the mentioned related information about each line in section of inclusion criteria or method, respectively. "Patients received no previous systemic treatment (ie, chemotherapy or others)" were defined as first line therapy. "Patients receive crizotinib after one prior platinum-based chemotherapy regimen" were defined as second line therapy. "Patients receive crizotinib first-line and/or some patients with second- 
line and/or others receive crizotinib more than one prior platinum-based chemotherapy regimen" were defined as mixed line therapy. The abstracts of the articles were independently reviewed by two authors $(\mathrm{H}$. $\mathrm{Hu}$ and $\mathrm{W}$. Q. Lin). Outcomes were pooled to obtain the ORR and PFS. Data were filtered and transferred into a standard electronic form. Any discrepancies were resolved by discussion until a consensus was reached. If an agreement was not reached, the principal investigator (Y. K. Kuang) made the final decision on the eligibility of the study and data extraction.

\section{Statistical analysis}

Stata Statistical Software, version 13.0 (Stata Corporation, College Station, TX, USA) was used to analyse the extracted data. Data were pooled statistically using the event rates calculated for ORR. The heterogeneity of the estimators was assessed with a $\chi^{2}$ test and the $\mathrm{I}^{2}$ statistic, which describes the percentage of the variability in effect estimates caused by heterogeneity [44]. Summary ORR and PFS estimates were based on random-effect models where $I^{2} \geq 50 \%$ and fixed models for $I^{2}<50 \%$. We considered that heterogeneity was present when the Cochran's $Q$-test $P$-value was $<0.05$. When results of two heterogeneity statistics are discrepant, to be more conservative, we considered that heterogeneity was present and random effects model was applied. All tests were 2-sided and statistical significance was defined as $p<0.05$. Finally, both the Begg's test and Egger's test were used to estimate potential publication bias $[45,46]$. A sensitivity analysis was used to verify value stability.

\section{Abbreviations}

ALK, anaplastic lymphoma kinase, CI, confidence interval, FDA, Food and Drug Administration, MeSH, medical subject heading, NOS, Newcastle Ottoman scale, NRCT, non-randomized controlled trial, RCT, randomized controlled trial, NSCLC, non-small cell lung cancer, ORR, overall response rate, PFS, progression-free survival, PS, performance status, EGFR, epidermal growth factor receptor, NCCN, National Comprehensive Cancer Network.

\section{ACKNOWLEDGMENTS}

All authors read and approved the final manuscript.

\section{CONFLICTS OF INTEREST}

The authors have declared no conflicts of interest.

\section{FUNDING}

None.

\section{REFERENCES}

1. GLOBOCAN 2012: Estimated CancerIncidence, Mortality and Prevalence Worldwide in 2012. http://globocan.iarc.fr/ Pages/fact_sheets_population.aspx?country=900. 2012.

2. Straughan DM, Azoury SC, Shukla V. Anaplastic Lymphoma Kinase Inhibitors in Non-Small Cell Lung Cancer: A Review of the Literature. Curr Drug Targets. 2015.

3. Kwak EL, Bang Y-J, Camidge DR, Shaw AT, Solomon B, Maki RG, Ou S-HI, Dezube BJ, Jaenne PA, Costa DB, Varella-Garcia M, Kim W-H, Lynch TJ, et al. Anaplastic Lymphoma Kinase Inhibition in Non-Small-Cell Lung Cancer. N Engl J Med. 2010; 363:1693-1703.

4. http://www.accessdata.fda.gov/drugsatfda_docs/ label/2013/202570s006lbl.pdf.

5. Camidge DR, Bang Y-J, Kwak EL, Iafrate AJ, VarellaGarcia M, Fox SB, Riely GJ, Solomon B, Ou S-HI, Kim D-W, Salgia R, Fidias P, Engelman JA, et al. Activity and safety of crizotinib in patients with ALK-positive nonsmall-cell lung cancer: updated results from a phase 1 study. Lancet Oncol. 2012; 13:1011-1019.

6. Shaw AT, Kim D-W, Nakagawa K, Seto T, Crino L, Ahn M-J, De Pas T, Besse B, Solomon BJ, Blackhall F, $\mathrm{Wu}$ Y-L, Thomas M, O'Byrne KJ, et al. Crizotinib versus Chemotherapy in Advanced ALK-Positive Lung Cancer. N Engl J Med. 2013; 368:2385-2394.

7. Solomon BJ, Mok T, Kim D-W, Wu Y-L, Nakagawa K, Mekhail T, Felip E, Cappuzzo F, Paolini J, Usari T, Iyer S, Reisman A, Wilner KD, et al. First-Line Crizotinib versus Chemotherapy in ALK-Positive Lung Cancer. N Engl J Med. 2014; 371:2167-2177.

8. White V. Pfizer's Phase 3 Xalkori NSCLC trial meets primary objective.

9. Qian H, Gao F, Wang H, Ma F. The efficacy and safety of crizotinib in the treatment of anaplastic lymphoma kinasepositive non-small cell lung cancer: a meta-analysis of clinical trials. BMC Cancer. 2014; 14.

10. Kim DW, Ahn MJ, Shi Y, De Pas TM, Yang PC, Riely GJ, Crino L, Evans TL, Liu X, Han JY, Salgia R, Lanzalone S, Polli A, et al. Results Of A Global Phase Ii Study With Crizotinib In Advanced Alk-Positive Non-Small-Cell Lung Cancer (NSCLC). Ann Oncol. 2012; 23:32-33.

11. Asao T, Honma Y, Suina K, Muraki K, Shukuya T, Ohashi R, Koyama R, Shimada N, Sakuraba S, Takahashi K. Efficacy And Toxicity Of Crizotinib For Patients With AlkPositive Advanced Nsclc. Ann Oncol. 2013; 24.

12. Perol M, Cadranel J, Planchard D, Dansin E, BigayGame L, Audigier-Valettee C, Scherpereel A, Buturuga A, Moro-Sibilot D, Besse B. Safety and efficacy profile of crizotinib in the French Temporary Authorization for Use (ATU) of crizotinib in patients (pts) with ALK-positive (+) advanced NSCLC. Eur J Cancer. 2013; 49:S799-S799.

13. Cao Y, Xiao G, Qiu X, Ye S, Lin T. Efficacy and Safety of Crizotinib among Chinese EML4-ALK-Positive, Advanced- 
Stage Non-Small Cell Lung Cancer Patients. PLoS One. 2014; 9:1-7.

14. Hernandez B, Martinez M, Teijeira L, Guerrero D, Mata E, Gil I, Castillo A, Verdun J, Antonio Rivadeneira J, Ochoa P, Aznarez E, Morilla I, De La Cruz S, et al. Crizotinib in advanced ALK-positive non-small cell lung cancer: Results of a retrospective cohort in Complejo Hospitalario de Navarra, Spain. J Clin Oncol. 2014; 32.

15. Cui S, Zhao Y, Gu A, Ge X, Song Y, Zhang W, Lou Y, Dong L, Han B, Jiang L. Efficacy and tolerability of crizotinib in the treatment of ALK-positive, advanced nonsmall cell lung cancer in Chinese patients. Med Oncol. $2015 ; 32$.

16. Cui S, Zhao Y, Dong L, Gu A, Xiong L, Qian J, Zhang W, Niu Y, Pan F, Jiang L. Is there a progression-free survival benefit of first-line crizotinib versus standard chemotherapy and second-line crizotinib in ALK-positive advanced lung adenocarcinoma? A retrospective study of Chinese patients. Cancer Med. 2016.

17. Zhang Q, Qin N, Wang J, Lv J, Yang X, Li X, Nong J, Zhang $\mathrm{H}$, Zhang $\mathrm{X}, \mathrm{Wu} \mathrm{Y}$, Zhang S. Crizotinib versus platinum-based double-agent chemotherapy as the first line treatment in advanced anaplastic lymphoma kinase-positive lung adenocarcinoma. Thoracic Cancer. 2016; 7:3-8.

18. Brosnan EM, Weickhardt AJ, Lu X, Maxon DA, Baron AE, Chonchol M, Camidge DR. Drug-induced reduction in estimated glomerular filtration rate in patients with ALKpositive non-small cell lung cancer treated with the ALK inhibitor crizotinib. Cancer. 2014; 120:664-674.

19. Lei YY, Yang JJ, Zhong WZ, Chen HJ, Yan HH, Han JF, Yang LL, Wu YL. Clinical efficacy of crizotinib in Chinese patients with ALK-positive non-small-cell lung cancer with brain metastases. J Thorac Dis. 2015; 7:1181-1188.

20. Blackhall F, Shaw AT, Jaenne PA, Kim DW, Wilner KD, Schnell P, Polli A, Besse B. Crizotinib safety profile in elderly and non-elderly patients (pts) with advanced ALK plus non-small cell lung cancer (NSCLC). Eur J Cancer. 2013; 49:S821-S821.

21. Chiari R, Metro G, Iacono D, Bellezza G, Rebonato A, Dubini A, Sperduti I, Bennati C, Paglialunga L, Burgio MA, Baglivo S, Giusti R, Minotti V, et al. Clinical impact of sequential treatment with ALK-TKIs in patients with advanced ALK-positive non-small cell lung cancer: Results of a multicenter analysis. Lung Cancer. 2015; 90:255-260.

22. Gainor JF, Tan DS, De Pas T, Solomon BJ, Ahmad A, Lazzari C, de Marinis F, Spitaleri G, Schultz K, Friboulet L, Yeap BY, Engelman JA, Shaw AT. Progression-Free and Overall Survival in ALK-Positive NSCLC Patients Treated with Sequential Crizotinib and Ceritinib. Clin Cancer Res. 2015; 21:2745-2752.

23. Okamoto I, Nakagawa K, Ohe Y, Ueno N, Banno S, Endo Y, Ohki E, Gemma A. Safety of crizotinib in 892 Japanese ALK-positive advanced NSCLC patients: Interim report of post-marketing surveillance. Ann Oncol. 2015; 26:37-37.
24. Crino L, Kim D, Riely GJ, Janne PA, Blackhall FH, Camidge DR, Hirsh V, Mok T, Solomon BJ, Park K, Gadgeel SM, Martins R, Han J, et al. Initial phase II results with crizotinib in advanced ALK-positive non-small cell lung cancer (NSCLC): PROFILE 1005. J Clin Oncol. 2011; 29.

25. Kim D, Ahn M, Yang P, Liu X, De Pas T, Crino L, Lanzalone S, Polli A, Shaw A. Updated Results Of A Global Phase Ii Study With Crizotinib In Advanced Alk-Positive Non-Small Cell Lung Cancer (NSCLC). Ann Oncol. 2012; 23:402-402.

26. https://www.nccn.org/patients/guidelines/nscl/index. html\#84.

27. Zhou Wj, Zhang $X$, Cheng $C$, Wang F, Wang Xk, Liang Yj, To KKW, Zhou W, Huang Hb, Fu Lw. Crizotinib (PF02341066) reverses multidrug resistance in cancer cells by inhibiting the function of P-glycoprotein. Br J Pharmacol. 2012; 166:1669-1683.

28. Lei YY, Yang JJ, Zhang XC, Zhong WZ, Zhou Q, Tu HY, Tian HX, Guo WB, Yang LL, Yan HH, Chen HJ, Xie Z, $\mathrm{Su}$ J, et al. Anaplastic Lymphoma Kinase Variants and the Percentage of ALK-Positive Tumor Cells and the Efficacy of Crizotinib in Advanced NSCLC. Clin Lung Cancer. 2015.

29. Won JK, Keam B, Koh J, Cho HJ, Jeon YK, Kim TM, Lee SH, Lee DS, Kim DW, Chung DH. Concomitant ALK translocation and EGFR mutation in lung cancer: a comparison of direct sequencing and sensitive assays and the impact on responsiveness to tyrosine kinase inhibitor. Ann Oncol. 2015; 26:348-354.

30. Johung KL, Yeh N, Desai NB, Williams TM, Lautenschlaeger $\mathrm{T}$, Arvold ND, Ning MS, Attia A, Lovly CM, Goldberg S, Beal K, Yu JB, Kavanagh BD, et al. Extended survival and prognostic factors for patients with ALK-rearranged non-small-cell lung cancer and brain metastasis. J Clin Oncol. 2016; 34:123-129.

31. Katayama R, Shaw AT, Khan TM, Mino-Kenudson M, Solomon BJ, Halmos B, Jessop NA, Wain JC, Yeo AT, Benes C. Mechanisms of acquired crizotinib resistance in ALK-rearranged lung cancers. Sci Transl Med. 2012; 4:120ra117-120ra117.

32. Perez CA, Velez M, Raez LE, Santos ES. Overcoming the resistance to Crizotinib in patients with Non-Small Cell Lung Cancer harboring EML4/ALK translocation. Lung Cancer. 2014; 84:110-115.

33. Chiari R, Metro G, Iacono D, Bellezza G, Rebonato A, Dubini A, Sperduti I, Bennati C, Paglialunga L, Burgio MA, Baglivo S, Giusti R, Minotti V, et al. Clinical impact of sequential treatment with ALK-TKIs in patients with advanced ALK-positive non-small cell lung cancer: Results of a multicenter analysis. Lung Cancer. 2015; 90:255-260.

34. Simionato F, Frizziero M, Carbone C, Tortora G, Melisi D. Current Strategies to Overcome Resistance to ALKInhibitor Agents. Curr Drug Metab. 2015; 16:585-596.

35. https://clinicaltrials.gov/ct2/show/NCT02737501?term=bri gatinib\&rank=1. 
36. https://clinicaltrials.gov/ct2/show/NCT02075840?term=ale ctinib\&rank $=3$.

37. Kim DW, Mehra R, Tan DS, Felip E, Chow LQ, Camidge DR, Vansteenkiste J, Sharma S, De Pas T, Riely GJ, Solomon BJ, Wolf J, Thomas M, et al. Activity and safety of ceritinib in patients with ALK-rearranged nonsmall-cell lung cancer (ASCEND-1): updated results from the multicentre, open-label, phase 1 trial. Lancet Oncol. 2016.

38. Ou S-HI, Ahn JS, De Petris L, Govindan R, Yang JC-H, Hughes B, Lena H, Moro-Sibilot D, Bearz A, Ramirez SV, Mekhail T, Spira A, Bordogna W, et al. Alectinib in Crizotinib-Refractory ALK-Rearranged Non-Small-Cell Lung Cancer: A Phase II Global Study. Journal of clinical oncology. 2016; 34:661-668.

39. Shaw AT, Gandhi L, Gadgeel S, Riely GJ, Cetnar J, West H, Camidge DR, Socinski MA, Chiappori A, Mekhail T, Chao $\mathrm{BH}$, Borghaei H, Gold KA, et al. Alectinib in ALK-positive, crizotinib-resistant, non-small-cell lung cancer: a singlegroup, multicentre, phase 2 trial. Lancet Oncol. 2016; 17:234-242.

40. http://www.roche.com/dam/jcr:dde04e89-ff90-4d9d-b58383c8769292bd/de/med-cor-2016-10-04-e.pdf.
41. Liberati A, Altman DG, Tetzlaff J, Mulrow C, Gøtzsche PC, Ioannidis JP, Clarke M, Devereaux PJ, Kleijnen J, Moher D. The PRISMA statement for reporting systematic reviews and meta-analyses of studies that evaluate health care interventions: explanation and elaboration. Ann Intern Med. 2009; 151:W-65-W-94.

42. Wells G, Shea B, O'Connell D, Robertson J, Peterson J, Welch V, Losos M, Tugwell P. The Newcastle-Ottawa Scale (NOS) for assessing the quality of nonrandomised studies in meta-analyses.

43. Higgins JP, Altman DG, Gotzsche PC, Juni P, Moher D, Oxman AD, Savovic J, Schulz KF, Weeks L, Sterne JA. The Cochrane Collaboration's tool for assessing risk of bias in randomised trials. BMJ. 2011; 343:d5928.

44. Higgins J, Thompson SG. Quantifying heterogeneity in a meta-analysis. Stat Med. 2002; 21:1539-1558.

45. Begg CB, Mazumdar M. Operating characteristics of a rank correlation test for publication bias. Biometrics. 1994:1088-1101.

46. Egger M, Smith GD, Schneider M, Minder C. Bias in metaanalysis detected by a simple, graphical test. BMJ. 1997; 315:629-634. 